\title{
PENGARUH KARAKTERISTIK TIPE KEPRIBADIAN DAN IPK TERHADAP KECEMASAN BERKOMPUTER MAHASISWA AKUNTANSI DALAM MENGGUNAKAN SOFTWARE AKUNTANSI DENGAN LOCUS OF CONTROL SEBAGAI VARIABEL MODERASI
}

\author{
Restu Winarni \\ Alumni Prodi Akuntansi Universitas negeri Yogyakarta \\ restuwinarni@yahoo.com \\ Diana Rahmawati \\ Jurusan Pendidikan Akuntansi Universitas Negeri Yogyakarta
}

\begin{abstract}
Abstrak: Pengaruh Karakteristik Tipe Kepribadian dan IPK terhadap Kecemasan Berkomputer Mahasiswa Akuntansi dalam Menggunakan Software Akuntansi dengan Locus of Control sebagai Variabel Moderasi. Penelitian ini bertujuan mengetahui: (1) Pengaruh karakteristik tipe kepribadian terhadap kecemasan berkomputer mahasiswa akuntansi dalam menggunakan software akuntansi, (2) Pengaruh IPK terhadap kecemasan berkomputer mahasiswa akuntansi dalam menggunakan software akuntansi, (3) Pengaruh kakteristik tipe kepribadian dan IPK terhadap kecemasan berkomputer mahasiswa akuntansi dalam menggunakan software akuntansi, (4) Pengaruh karakteristik tipe kepribadian terhadap kecemasan berkomputer mahasiswa akuntansi dalam menggunakan software akuntansi dengan locus of control sebagai variabel moderasi, (5)Pengaruh IPK terhadap kecemasan berkomputer berkomputer mahasiswa akuntansi dalam menggunakan software akuntansi dengan $L O C$ sebagai variabel moderasi, (6)Pengaruh karakteristik tipe kepribadian dan IPK terhadap kecemasan berkomputer mahasiswa akuntansi dalam menggunakan software akuntansi dengan LOC sebagai variabel moderasi. Berdasarkan hasil penelitian menunjukkan (1) Terdapat pengaruh karakteristik tipe kepribadian terhadap kecemasan berkomputer dalam menggunakan software akuntansi, dibuktikan $\mathrm{t}_{\text {hitung }} 4,465>\mathrm{t}_{\text {tabel }} 1,9781$ dan $\mathrm{r}=0,377$. (2) Terdapat pengaruh IPK terhadap kecemasan berkomputer dalam menggunakan software akuntansi, dibuktikan $t_{\text {hitung }} 2,972>$ $t_{\text {tabel }} 1,9781$ dan $r=0,252$. (3) Terdapat pengaruh karakteristik tipe kepribadian dan IPK terhadap kecemasan berkomputer dalam menggunakan software akuntansi, dibuktikan $F_{\text {hitung }} 14,436>F_{\text {tabel }}$ 3,91 dan $\mathrm{R}=0,428$. (4) Terdapat pengaruh karakteristik tipe kepribadian terhadap kecemasan berkomputer dalam menggunakan software akuntansi dengan $L O C$ sebagai variabel moderasi, dibuktikan signifikasi variabel moderasi $0,013<0,05$. Nilai $F_{\text {hitung }} 14,495>F_{\text {tabel }} 3,91$ dan $R=0,377$. (5) Terdapat pengaruh IPK terhadap kecemasan berkomputer dalam menggunakan software akuntansi dengan $L O C$ sebagai variabel moderasi, dibuktikan signifikasi variabel moderasi $0,027<0,05$. Nilai $\mathrm{F}_{\text {hitung }} 6,545>\mathrm{F}_{\text {tabel }} 3,91$ dan $\mathrm{R}=0,365$. (6) Terdapat pengaruh karakteristik tipe kepribadian dan IPK terhadap kecemasan berkomputer dalam menggunakan software akuntansi dengan LOC sebagai variabel moderasi, dibuktikan signifikasi variabel moderasi $0,023<0,05$. Nilai $F_{\text {hitung }} 12,031>F_{\text {tabel }}$ 3,92 dan $\mathrm{R}=0,524$.
\end{abstract}

Kata Kunci: Karakteristik Tipe Kepribadian, IPK, Kecemasan Berkomputer, Locus of Control

\begin{abstract}
The Influence of Characteristics of Personality Type and GPA to Computer Anxiety of Accounting Students in Using Accounting Software with Locus of Control as a Moderating Variable. The aim of this research is to know: (1) the influence of characteristics of personality type to computer anxiety of accounting students in using accounting software, (2) the influence of GPA to computer anxiety of accounting students in using accounting software, ( 3 ) the influence of characteristic of personality type and GPA to computer anxiety of accounting students in using accounting software, (4) the influence of characteristic of personality type to computer anxiety of accounting students in using accounting software with locus of control as a moderating variable, (5) the influence of GPA to computer anxiety of accounting students in using accounting software with locus of control as a moderating variable, ( 6 ) the influence of characteristic of personality type and
\end{abstract}




\section{JURNAL NOMINAL / VOLUME IV NOMOR 1 / TAHUN 2015}

GPA to computer anxiety of accounting students in using accounting software with locus of control as a moderating variable. The results shows that ( 1 ) Found an influence of characteristics of personality type to computer anxiety of accounting students in using accounting software, its showed byt count $=4,465>t$ table $=1.9781$ and correlation value $(r)$ of 0.377. (2) Found an influence of GPA to computer anxiety of accounting students in using accounting software, its showed by $t$ count $=$ 2,972 >t table $=1.9781$ and correlation value ( $r$ ) of 0.252. ( 3 ) Found aninfluence of characteristic of personality type and GPA to computer anxiety of accounting students in using accounting software, its showed from the value of $F 14.436>F$ table 3,91 and correlation value (R) of 0.428.( 4 ) Found an influence of characteristic of personality type to computer anxiety of accounting students in using accounting software with locus of control as a moderating variable, its showed from the value of $F$ $14.495>F$ table 3,91 and correlation value $(R)$ of 0.377.( 5 ) Found an influence of GPA to computer anxiety of accounting students in using accounting software with locus of control as a moderating variable, its showed from the value of $F$ 6,545 $>F$ table 3,91 and correlation value $(R)$ of 0.365.( 6 ) Found an influence of GPA to computer anxiety of accounting students in using accounting software with locus of control as a moderating variable, its showed from the value of $F 12,031>F$ table 3,92 and correlation value $(R)$ of 0.524 .

Keywords: Characteristic of Personality Type, GPA, Computer Anxiety, Locus of Control

\section{PENDAHULUAN}

Teknologi merupakan salah satu komponen penting dari sistem informasi. Sistem informasi tidak akan dapat menghasilkan informasi tepat waktu tanpa adanya dukungan dari teknologi. Komponen teknologi dapat mempercepat sistem informasi dalam pengolahan data. Perkembangan sistem informasi berbasis komputer mengalami perubahan yang signifikan.

Dengan adanya perkembangan teknologi komputer, organisasi perlu mempersiapkan sumber daya manusia. Menyadari pentingnya penguasaan teknologi komputer dalam dunia bisnis, mahasiswa diharapkan mempelajari teknologi komputer untuk dapat meningkatkan karir mahasiswa kelak. Hal ini dilakukan dengan mengintegrasikan penggunaan komputer ke dalam kurikulum pengajaran akuntansi.Salah satunya adalah dengan menerapkan software bisa dikatakan sebagai otak dari sistem informasi.Salah satu software yang diterapkan adalah software akuntansi.

Software akuntansi merupakan salah satu produk teknologi informasi yang harus dikuasai oleh mahasiswa khususnya mahasiswa jurusan akuntansi, karena memberikan kemungkinan positif dalam meningkatkan nilai jual mahasiswa di dunia kerja.

Mahasiswa akuntansi mengikuti mata kuliah Komputer Akuntansi mempelajari software akuntansi secara teori dan praktek.Software akuntansi yang dipelajari memiliki manfaat yang terkadang kurang disadari oleh mahasiswa akuntansi, sebagian dari mereka mengikuti mata kuliah Komputer Akuntansi hanya karena sebuah kewajiban untuk mempelajarinya. Banyak manfaat yang diperoleh mahasiswa akuntansi dalam mempelajari dan menggunakan software akuntansi, keahlian 


\section{JURNAL NOMINAL / VOLUME IV NOMOR 1 / TAHUN 2015}

dan pengetahuan teoritis mahasiswa akan semakin lengkap sehingga kelak saat lulus akan mempunyai bekal kerja yang cukup untuk masuk ke dunia bisnis.

Adanya perkembangan baru teknologi informasi, seorang mahasiswa dapat menyikapi kehadiran komputer secara berbeda dan kadang mahasiswa menyikapi dengan penolakan. Penolakan ini juga disebabkan oleh kegelisahan yang mendalam atau ketakutan berlebih terhadap teknologi komputer yang sering disebut computerphobia.

Computer anxiety merupakan sifat individu yang mengalami kecemasan terhadap adanya komputer.Kecemasan berkomputer pada mahasiswa dapat menjadi penghalang untuk mahasiswa dalam mengembangkan dirinya untuk lebih memahami teknologi informasi termasuk didalamnya software akuntansi.

Tingkat kecemasan berkomputer yang ada pada setiap individu berbeda-beda menurut tipe kepribadian mereka.Setiap individu memiliki karakteristik tipe kepribadian yang berbeda. Carl Gustav Jung (1921) dalam Syaiful Ali dan Fadila (2008) telah menguji dalam literatur psikologi yang menyatakan bahwa bagaimana seseorang merasakan, mengevaluasi atau menilai situasi., ketrampilan, nilai-nilai serta reaksi mereka termasuk reaksi terhadap komputer.

Teori kepribadian yang dikemukakan oleh Jung (1921) dalam Ladislaus Naisaban
(2003), Katherine C. Briggs dan Isabel Briggs Myers mengembangkan teori kepribadian Jung kemudian membuat alat ukur kepribadian yang dinamakan Myers Briggs Type Indicator (MBTI). MBTI digunakan untuk mengidentifikasi, dari laporan diri seseorang, untuk mengenali reaksinya dengan mudah juga menjadi preferensi dasar dari individu tentang persepsi dan judgment-nya.

Menurut Reno dan Wiwik (2003) mahasiswa dengan IPK yang tinggi akan lebih mampu mengikuti mata kuliah yang harus ditempuh dan mereka lebih siap dalam menerima materi baru. Mahasiswa yang memiliki IPK tinggi akan akan lebih siap menerima hal baru yang membuat kecemasan mereka terhadap komputer akan lebih rendah dibandingkan dengan mahasiswa yang mempunyai IPK rendah. Sehingga perolehan IPK oleh mahasiswa dapat mempengaruhi tingkat kecemasan berkomputer mahasiswa.

Ketakutan dan kekuatiran individu muncul akibat konsep cara pandang individu terhadap keadaan saat ini. Indriantoro (1993) dalam Ronowati Tjandra (2007) menyebutkan faktor penguasaan dan cara pandang individu sebagai faktor locus of control. Individu yang memiliki internal locus of control berpandangan bahwa peristiwa-peristiwa yang akan terjadi diakibatkan oleh keputusan-keputusan yang dimilikinya. External locus of control 


\section{JURNAL NOMINAL / VOLUME IV NOMOR 1 / TAHUN 2015}

menyebabkan individu merasa tidak mampu menguasai keadaan sehingga timbul kecemasan (anxiety).Jadi variabel locus of control dapat dijadikan variabel moderasi dalam menentukan pengaruh karakteristik individu terhadap kecemasan berkomputer mahasiswa.

Berdasarkan uraian sebelumnya, maka penulis tertarik untuk menulis skripsi dengan judul "Pengaruh Karakteristik Tipe Kepribadian dan IPK terhadap Kecemasan Berkomputer Mahasiswa Akuntansi dalam Menggunakan Software Akuntansi dengan Locus Of Control Sebagai Variabel Moderasi (Studi Kasus pada Mahasiswa Prodi Akuntansi Universitas Negeri Yogyakarta).”

\section{METODE PENELITIAN}

\section{Jenis Penelitian}

Metode penelitian yang digunakan dalam mencari dan mengolah data adalah penelitian kuantitatif. Jenis penelitian ini adalah penelitian asosiatif dengan unit analisis yang diteliti adalah mahasiswa akuntansi yang sedang atau sudah mempuh mata kuliah Komputer Akuntansi dan Sistem Informasi Akuntansi. Metode pengukuran dalam penelitian ini menggunakan skala model Likert.

\section{Waktu dan Tempat Penelitian}

Penelitian dilakukan di Universitas Negeri Yogyakarta pada bulan Februari 2015.

\section{Populasi}

Populasi pada penelitian ini adalah mahasiswa Akuntansi SI angkatan 2011 dan 2012 FE Universitas Negeri Yogyakarta yang masih aktif kuliah dan yang sudah menempuh mata kuliah Komputer Akuntansi dan Sistem Informasi Akuntansi yang berjumlah 196 orang.

\section{Definisi Operasional Variabel}

a. Kecemasan Berkomputer Mahasiswa dalam Menggunakan Software Akuntansi Kecemasan berkomputer computer anxiety) dalam menggunakan software akuntansi dapat diartikan sebagai sifat individu yang mengalami kegelisahan atau kecemasan terhadap adanya komputer yaitu dalam penggunaan software akuntansi. Kecemasan berkomputer mahasiswa akuntansi dalam menggunakan software akuntansi berhubungan dengan ketakutan yang berlebihan terhadap penggunaan komputer dalam menjalankan software akuntansi. Indikator variabel ini adalah fear dan anticipation .

b. Karakteristik Tipe Kepribadian

Karakteristik tipe kepribadian dapat didefinisikan sebagai ciri-ciri atau karakter yang bersifat internal, relatif permanen, menuntun, mengarahkan dan mengorganisir aktivitas manusia yang dapat menunjukkan sifat dari seseorang dalam hal pikiran, kegiatan dan perasaan. Indikator variabel ini adalah (1) Extrovert (E) vs. Introvert (I), (2) 
Sensing (S) vs. Intuitive (N), (3) Thinking

(T) vs. Feeling (F), dan (4) Judging (J) vs.

Perceiving (P).

c. IPK

Indeks Prestasi Kumulatif (IPK) merupakan rata-rata nilai yang diperoleh mahasiswa dari tiap semester yang telah ditempuhnya.

d. Locus of Control

Locus of Control merupakan kendali individu atas suatu pekerjaan mereka dan kepercayaan mereka terhadap keberhasilan diri. Locus of control terdiri dari dua bagian yaitu internal locus of control dan external locus of control.

\section{Teknik Pengumpulan Data}

Metode pengumpulan data dalam penelitian ini adalah dengan menggunakan kuesioner. Kuesioner berisi tentang variable kecemasan berkomputer mahasiswa akuntansi dalam menggunakan software akuntansi, karakteristik tipe kepribadian, IPK dan locus of control.

\section{Teknik Analisis Data}

a. Uji Prasyarat Analisis

1) Uji Normalitas

Uji normalitas bertujuan untuk mengetahui apakah variabel-variabel dalam penelitian memiliki sebaran distribusi normal atau tidak. Uji normalitas ini menggunakan teknik Kolmogrov-Smirnov..
Data dikatakan normal apabila nilai signifikansi $>0,05$.

2) Uji Linieritas

Uji Linieritas digunakan untuk mengetahui apakah variabel bebas dengan variabel terikat mempunyai hubungan linier atau tidak. Pengujian menggunakan Test for Linearity dengan taraf signifikansi 0,05 . Dua variabel dikatakan mempunyai hubungan yang linier bila signifikansinya kurang dari 0,05.

\section{b. Uji Asumsi Klasik}

1) Uji Heteroskedastisitas

Uji heteroskedastisitas bertujuan untuk menguji apakah dalam regresi terjadi ketidaksamaan varian dari residual satu pengamatan ke pengamatan lain. Hal ini dapat dilihat apabila dari probabilitas signifikansinya di atas 0,05.

2) Uji Multikolinieritas

Uji multikolinieritas digunakan untuk mengetahui ada tidaknya multikolinieritas dengan menyelidiki besarnya inter kolerasi antar variabel bebasnya. Ada tidaknya multikolinieritas dapat dilihat dari besarnya Tolerance Value $\geq 0,10$ atau sama dengan nilai VIF $\leq 10$ maka tidak terjadi multikolinieritas.

\section{Uji Hipotesis}

1) Analisis Regresi Sederhana

Persamaan regresi sederhana dapat digunakan untuk melakukan prediksi 


\section{JURNAL NOMINAL / VOLUME IV NOMOR 1 / TAHUN 2015}

seberapa tinggi hubungan kausal satu variabel independen dengan satu variabel dependen. Dalam analisis regresi sederhana, langkah-langkah yang harus ditempuh adalah sebagai berikut:

a) Membuat garis regresi linear sederhana

b) Menguji signifikansidengan uji t

2) Analisis Regresi Berganda

Analisis regresi linear berganda merupakan analisis untuk mengetahui pengaruh variabel independen yang jumlahnya lebih dari satu terhadap satu variabel dependen.

3) Moderated Regression Analysis (MRA)

Analisis Moderated Regression Analysis (MRA) atauuji interaksi merupakan aplikasi khusus regresi berganda linear dimana dalam persamaan regresinya mengandung unsur interaksi (perkalian dua atau lebih variabel independen).

HASIL PENELITIAN DAN PEMBAHASAN

\section{Statistik Deskriptif}

a. Variabel Kecemasan Berkomputer Mahasiswa Akuntansi dalam Menggunakan Software Akuntansi

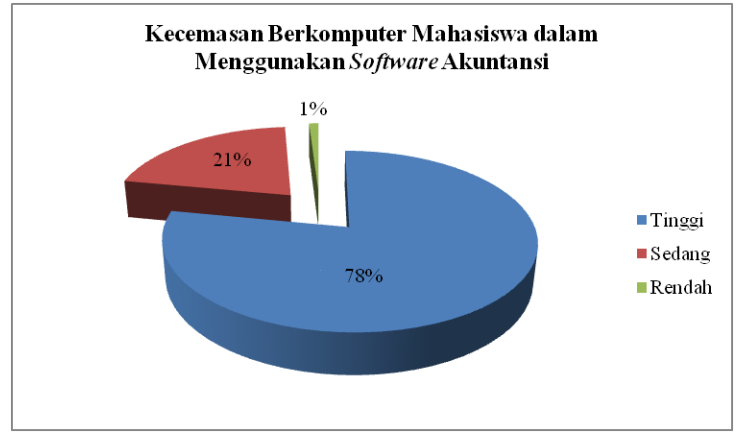

Gambar 1. Pie Chart Kecenderungan Data Variabel

Kecemasan

Berkomputer

Pie Chart menunjukkan bahwa kategori tinggi sebanyak 103 responden (78\%), kategori sedang sebanyak 28 responden (21\%), dan kategori rendah sebanyak 1 responden (1\%). Sehingga penilaian responden tentang variabel ini adalah tinggi karena mayoritas responden memberikan penilaian tinggi.

b. Variabel Karakteristik Tipe Kepribadian

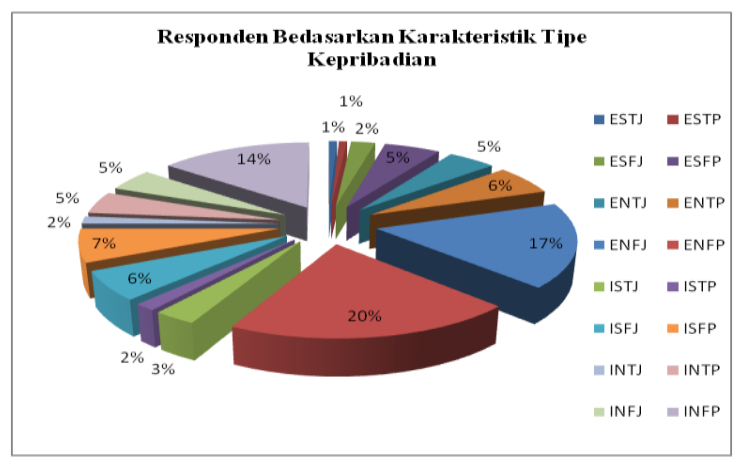

Gambar 2. Pie Chart Kecenderungan Data Variabel Karakteristik Tipe Kepribadian.

Pie Chart menunjukkan bahwa kategori ESTJ sebanyak 1 responden (1\%), kategori ESTP sebanyak 1 responden (1\%), kategori 


\section{JURNAL NOMINAL / VOLUME IV NOMOR 1 / TAHUN 2015}

ESFJ sebanyak 3 responden (2\%), kategori ESFP sebanyak 7 responden (5\%), kategori ENTJ sebanyak 6 responden (5\%), kategori ENTP sebanyak 8 responden (6\%), kategori ENFJ sebanyak 23 responden (17\%), kategori ENFP sebanyak 27 responden (20\%), kategori ISTJ sebanyak 4 responden (3\%), kategori ISTP sebanyak 2 responden (2\%), kategori ISFJ sebanyak 8 responden (6\%), kategori ISFP sebanyak 9 responden (7\%), kategori INTJ sebanyak 2 responden (2\%), kategori INTP sebanyak 6 responden (5\%), kategori INFJ sebanyak 6 responden (5\%) dan kategori INFP sebanyak 19 responden (14\%). Sehingga responden mayoritas mempunyai karakteristik tipe kepribadian ENFP. Seseorang yang bersifat ENFP (Extrovet Intuitive Feeling Preceiving).

\section{c. Variabel IPK}

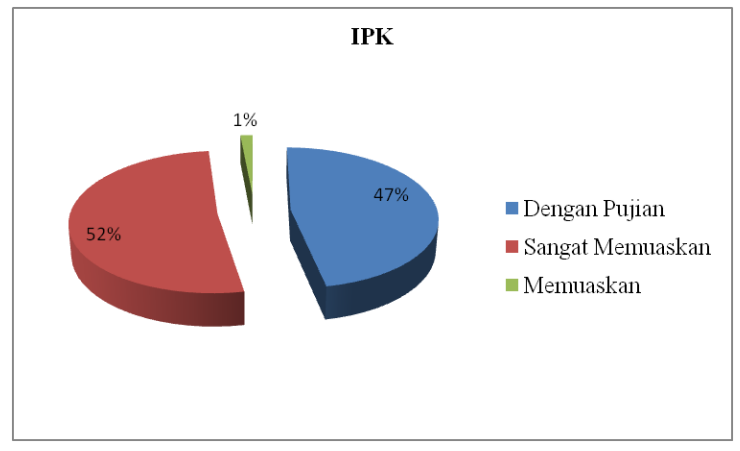

Gambar 3. Pie Chart Kecenderungan Data Variabel IPK

Pie Chartmenunjukkan bahwa kategori degan pujian sebanyak 62 responden $(47 \%)$, kategori sangat memuaskan sebanyak 68 responden $(52 \%)$ dan kategori memuaskan sebanyak 2 responden (2\%). Sehingga mayoritas responden mendapat IPK dalam kategori sangat memuaskan.

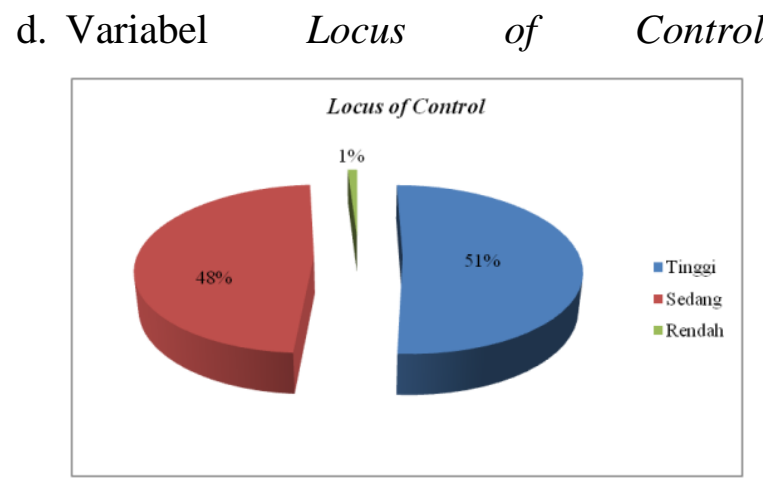

Gambar 3. Pie Chart Kecenderungan Data Variabel Locus of Control

Pie Chart menunjukkan menunjukkan bahwa kategori tinggi sebanyak 67 responden (51\%), kategori sedang sebanyak 64 responden (48\%) dan kategori rendah sebanyak 1 responden (1\%). Sehingga penilaian responden tentang variabel locus of control adalah tinggi karena mayoritas responden memberikan penilaian tinggi.

\section{Hasil Uji Prasyarat Analisis}

a. Uji Normalitas

Tabel 1. Hasil Uji Normalitas

\begin{tabular}{rcc}
$\begin{array}{c}\text { Kolmogrov- } \\
\text { Smirnov Z }\end{array}$ & Sig & Keterangan \\
\hline 0,863 & 0,445 & Data Normal \\
\hline
\end{tabular}

Sumber: Data primer yang diolah

Berdasarkan tabel di atas, dapat diketahui nilai signifikansinya sebesar 
0,445. Angka tersebut lebih besar dari 0,05, sehingga data dikatakan normal dan dapat digunakan untuk uji selanjutnya.

\section{b. Hasil Uji Linieritas}

Tabel 2. Hasil Uji Linieritas

\begin{tabular}{lcc}
\hline \multicolumn{1}{c}{ Variabel } & Linearity & Ket \\
\hline Karakteristik Tipe & 0,000 & Linier \\
Kepribadian & & \\
\hline IPK & 0,005 & Linier \\
\hline Locus of Control & 0,000 & Linier
\end{tabular}

Sumber: Data primer yang diolah

Berdasarkan tabel di atas menunjukkan bahwa Linearity untuk ketiga hubungan memiliki nilai signifikansi kurang dari 0,05. Sehingga hubungan antara variabel Independen dan dependen adalah linier.

\section{Hasi Uji Asumsi Klasik}

a. Hasil Uji Heteroskedastisitas

Tabel 3. Hasil Uji Heteroskedastisitas

\begin{tabular}{lcl}
\hline \multicolumn{1}{c}{ Variabel } & Sig & \multicolumn{1}{c}{ Keterangan } \\
\hline Karakteristik & 0,907 & $\begin{array}{l}\text { Tidak terjadi } \\
\text { heteroskedastisitas } \\
\text { Tipe }\end{array}$ \\
Kepribadian & & \\
\hline IPK & 0,308 & Tidak terjadi \\
& & heteroskedastisitas \\
\hline $\begin{array}{l}\text { Locus of } \\
\text { Control }\end{array}$ & 0,653 & $\begin{array}{l}\text { Tidak terjadi } \\
\text { heteroskedastisitas }\end{array}$ \\
\hline
\end{tabular}

Sumber: Data primer yang diolah
Berdasarkan tabel di atas menunjukkan bahwa seluruh variabel bebas mempunyai nilai probabilitas signifikansi lebih besar dari 0,05 . Sehingga seluruh variabel bebas tidak terjadi heteroskedastisitas.

b. Hasil Uji Multikolinieritas

Tabel 4. Hasil Uji Multikolinieritas

\begin{tabular}{lcl}
\hline \multicolumn{1}{c}{ Variabel } & VIF & \multicolumn{1}{c}{ Keterangan } \\
Karakteristik & 1,022 & $\begin{array}{l}\text { Tidak terjadi } \\
\text { multikolinieritas }\end{array}$ \\
Tipe & & \\
Kepribadian & & \\
\hline IPK & 1,038 & $\begin{array}{l}\text { Tidak terjadi } \\
\text { multikolinieritas }\end{array}$ \\
& & Tidak terjadi \\
Locus of & 1,021 & multikolinieritas
\end{tabular}

Sumber: Data primer yang diolah

Berdasarkan tabel di atas menunjukkan semua variabel bebas mempunyai nilai Tolerance $\geq 0,10$ dan nilai VIF $\leq 10$. Sehingga seluruh variabel bebas dalam penelitian ini tidak terjadi multikolinieritas.

\section{Hasil Uji Hipotesis}

a. Uji Regresi Linier Sederhana

1) H1 : Terdapat pengaruh karakteristik tipe kepribadian terhadap kecemasan berkomputer mahasiswa akuntansi dalam menggunakan software akuntansi. 
Tabel 5. Rangkuman Hasil Analisis Regresi Sederhana $\mathrm{X}_{1}$

\begin{tabular}{lccc}
\hline \multicolumn{1}{c}{ Variabel } & $\begin{array}{c}\text { Koefisien } \\
\text { Regresi }\end{array}$ & thitung & Sig \\
& & \\
\hline Konstanta & 59,817 & & \\
\hline Karakteristik & 0,979 & 4,645 & 0,000 \\
Tipe & & & \\
Kepribadian & & & \\
\hline r: 0,377 & & & \\
\hline
\end{tabular}

$R$ Square : 0,142

Sumber : Data primer yang diolah

a) Persamaan Garis Regresi

Berdasarkan hasil perhitungan regresi linier sederhana, maka persamaan regresinya adalah sebagai berikut:

$\mathrm{Y}=59,817+0,979 \mathrm{X}_{1}$

Nilai koefisien regresi $X_{1}$ sebesar 0,979 menyatakan bahwa setiap kenaikan karakteristik tipe kepribadian sebesar 1 satuan akan meningkatkan kecemasan berkomputer mahasiswa akuntansi dalam menggunakan software akuntansi sebesar 0,979 satuan. Hal ini berarti arah model tersebut adalah positif. Hal ini dapat dilihat dari nilai korelasi regresi (r) sebesar 0,377. Koefisien determinasi $\left(\mathrm{R}^{2}\right)$ sebesar 0,142 hal ini menunjukkan 14,2\% tingkat kecemasan berkomputer mahasiswa akuntansi dalam menggunakan software akuntansi dipengaruhi oleh karakteristik tipe kepribadian, sedangkan sisanya sebesar
$86,4 \%$ dipengaruhi oleh variabel lain di luar penelitian ini.

b) Uji t

Nilai $t_{\text {hitung }}=4,465>t_{\text {tabel }}=1,9781$, hal ini berarti terdapat pengaruh karakteristik tipe kepribadian terhadap kecemasan berkomputer mahasiswa akuntansi dalam menggunakan software akuntansi. Sehingga hipotesis pertama yang menyatakan bahwa terdapat pengaruh karakteristik tipe kepribadian terhadap kecemasan berkomputer mahasiswa akuntansi dalam menggunakan software akuntansi diterima.

2) H2 : Terdapat pengaruh IPK terhadap kecemasan berkomputer mahasiswa akuntansi dalam menggunakan software akuntansi.

Tabel 6. Rangkuman Hasil Analisis Regresi Sederhana $\mathrm{X}_{1}$

$\begin{array}{ccc}\text { Variabel } & \text { Koefisien } \\ & \text { Regresi } & \\ & & \end{array}$

\begin{tabular}{lccc}
\hline Konstanta & 38,826 & & \\
\hline IPK & 9,204 & 2,972 & 0,004
\end{tabular}

$r: 0,252$

$R$ Square : 0,064

Sumber : Data primer yang diolah

a) Persamaan Garis Regresi

Berdasarkan hasil perhitungan regresi linier sederhana yang ditunjukkan 


\section{JURNAL NOMINAL / VOLUME IV NOMOR 1 / TAHUN 2015}

pada Tabel di atas, maka persamaan regresinya adalah sebagai berikut:

$$
Y=38,826+9,204 X_{2}
$$

Nilai koefisien regresi $\mathrm{X}_{1}$ sebesar 9,204 menyatakan bahwa setiap kenaikan IPK sebesar 1 satuan akan meningkatkan kecemasan berkomputer mahasiswa akuntansi dalam menggunakan software akuntansi sebesar 9,204 satuan. Hal ini berarti arah model tersebut adalah positif. Hal ini dapat dilihat dari nilai korelasi regresi (r) sebesar 0,252. Koefisien determinasi $\left(\mathrm{R}^{2}\right)$ sebesar 0,064 hal ini menunjukkan $6,4 \%$ tingkat kecemasan berkomputer mahasiswa akuntansi dalam menggunakan software akuntansi dipengaruhi oleh karakteristik tipe kepribadian, sedangkan sisanya sebesar 93,6\% dipengaruhi oleh variabel lain di luar penelitian ini.

b) Uji t

Nilai $\mathrm{t}_{\text {hitung }}=2,972>\mathrm{t}_{\text {tabel }}=1,9781$, hal ini berarti terdapat pengaruh IPK terhadap kecemasan berkomputer mahasiswa akuntansi dalam menggunakan software akuntansi. Sehingga hipotesis kedua yang menyatakan bahwa terdapat pengaruh IPK terhadap kecemasan berkomputer mahasiswa akuntansi dalam menggunakan software akuntansi diterima. b. Uji Regresi Linier Berganda

H3 : Terdapat pengaruh karakteristik tipe kepribadian dan IPK terhadap kecemasan berkomputer mahaiswa akuntansi dalam menggunakan software akuntansi.

Tabel 7. Rangkuman Hasil Analisis Regresi Linier Berganda

\begin{tabular}{ll}
\hline \multicolumn{1}{c}{ Variabel } & Koefisien Regresi \\
\hline Konstanta & 34,877 \\
\hline Computer Anxiety & 0,905 \\
\hline Computer Attitude & 7,419 \\
\hline $\mathrm{R}$ & 0,428 \\
\hline Adjusted RSquare & 0,183 \\
\hline F hitung & 14,436 \\
\hline F table & 3,91 \\
\hline Sig F & 0,000
\end{tabular}

Sumber : Data primer yang diolah

1) Persamaan Garis Regresi

Berdasarkan hasil perhitungan regresi linier berganda yang ditunjukkan tabel di atas, maka persamaan garis regresinya seperti berikut:

$Y=34,877+0,905 X_{1}+7,419 X_{2}$

Nilai koefisien $\mathrm{X}_{1}$ sebesar 0,905 yang berarti karakteristik tipe kepribadian meningkat 1 poin maka kecemasan berkomputer mahasiswa akuntansi dalam menggunakan software akuntansi akan naik sebesar 0,905 satuan dengan asumsi $\mathrm{X}_{2}$ tetap. Nilai koefisien $\mathrm{X}_{2}$ sebesar 7,419 yang 
berarti IPK meningkat 1 poin maka kecemasan berkomputer mahasiswa akuntansi dalam menggunakan software akuntansi akan naik sebesar 7,419 satuan dengan asumsi $\mathrm{X}_{1}$ tetap. Hal ini berarti arah model tersebut adalah positif. Hal ini juga dapat dilihat dari nilai korelasi regresi $(\mathrm{R})$ sebesar 0,428 .

2) Uji F

Berdasarkan Tabel 7 diperoleh nilai $F_{\text {hitung }}=14,436>F_{\text {tabel }}=3,91$, maka dapat dinyatakan bahwa karakteristik tipe kepribadian dan IPK berpengaruh secara simultan terhadap kecemasan berkomputer mahasiswa akuntansi dalam menggunakan software akuntansi. Sehingga hipotesis ketiga yang menyatakan terdapat pengaruh karakteristik tipe kepribadian dan IPK berpengaruh secara simultan terhadap kecemasan berkomputer mahasiswa akuntansi dalam menggunakan software akuntansi diterima.

c. MRA

1) H4: Terdapat pengaruh karakteristik tipe kepribadian terhadap kecemasan berkomputer mahasiswa akuntansi dalam menggunakan software akuntansi dengan locus of control sebagai variabel moderasi.
Tabel 8. Rangkuman Hasil Analisis MRA

Variabel

Koefisien

Regresi

\begin{tabular}{lc}
\hline Konstanta & $-4,104$ \\
\hline Karakteristik Tipe & 4,592 \\
Kepribadian & \\
\hline Locus of Control & 1,342 \\
\hline Moderasi & $-0,077$ \\
\hline $\mathrm{R}$ & 0,504
\end{tabular}

\begin{tabular}{lc}
\hline RSquare & 0,254 \\
\hline F Hitung & 14,495
\end{tabular}

Sig F 0,000

Sig Karakteristik Tipe $\quad 0,002$

Kepribadian

\begin{tabular}{lc}
\hline Sig Locus of Control & 0,001 \\
\hline Sig Moderasi & 0,013
\end{tabular}

1) Persamaan Garis Regresi

Berdasarkan tabel di atas diperoleh persamaan untuk hipotesis 4 sebagai berikut:

$Y=-4,104+4,592 X_{1}+1,342 X_{3}-0,077$ $\mathrm{X}_{1} \mathrm{X}_{3}$

Nilai koefisien $X_{1}$ sebesar 4,592 dengan signifikansi 0,002 yang berarti karakteristik tipe kepribadian meningkat 1 poin maka kecemasan berkomputer mahasiswa akuntansi dalam menggunakan software akuntansi akan naik sebesar 4,592 satuan dengan asumsi $\mathrm{X}_{3}$ dan $\mathrm{X}_{1} \mathrm{X}_{3}$ tetap. Nilai koefisien $\mathrm{X}_{3}$ sebesar 4,592 dengan signifikansi 0,001 yang berarti locus of control meningkat 1 


\section{JURNAL NOMINAL / VOLUME IV NOMOR 1 / TAHUN 2015}

poin maka kecemasan berkomputer mahasiswa akuntansi dalam menggunakan software akuntansi akan naik sebesar 4,592 satuan dengan asumsi $X_{1}$ dan $X_{1} X_{3}$ tetap. Nilai koefisien $X_{1} X_{3}$ sebesar -0,077 dengan signifikansi 0,013 yang berarti variabel moderasi meningkat 1 poin maka kecemasan berkomputer mahasiswa akuntansi dalam menggunakan software akuntansi akan turun sebesar $-0,077$ satuan dengan asumsi $X_{1}$ dan $X_{3}$ tetap. Ketiga variabel ini mempunyai signifikansi di bawah 0,05, sehingga variabel Locus of Control dapat digunakan sebagai variabel moderasi dalam penelitian ini.

\section{2) Hasil Uji F}

Hasil penelitian ini diperoleh nilai $F_{\text {hitung }}=14,495>F_{\text {tabel }}=3,91$, maka dapat dinyatakan bahwa karakteristik tipe kepribadian berpengaruh terhadap kecemasan berkomputer mahasiswa akuntansi dalam menggunakan software akuntansi dengan locus of control sebagai varabel moderasi.

2) H5: Terdapat pengaruh IPK terhadap kecemasan berkomputer mahasiswa akuntansi dalam menggunakan software akuntansi dengan locus of control sebagai variabel moderasi.
Tabel 8. Rangkuman Hasil Analisis MRA

\begin{tabular}{lc}
\hline \multicolumn{1}{c}{ Variabel } & $\begin{array}{c}\text { Koefisien } \\
\text { Regresi }\end{array}$ \\
\hline Konstanta & $-0,849$ \\
\hline IPK & 15,845 \\
\hline Locus of Control & 0,911 \\
\hline Moderasi & $-0,164$ \\
\hline R & 0,365 \\
\hline RSquare & 0,133 \\
\hline F Hitung & 6,545 \\
\hline Sig F & 0,000 \\
\hline Sig IPK & 0,003 \\
\hline Sig Locus of Control & 0,007 \\
\hline Sig Moderasi & 0,027
\end{tabular}

1) Persamaan Regresi

Berdasarkan tabel di atas diperoleh persamaan untuk hipotesis 5 sebagai berikut:

$Y=-4,104+4,592 X_{1}+1,342 X_{3}-$ $0,077 \mathrm{X}_{1} \mathrm{X}_{3}$

Nilai koefisien $X_{2}$ sebesar 15,845 dengan signifikansi 0,003 yang berarti IPK meningkat 1 poin maka kecemasan berkomputer mahasiswa akuntansi dalam menggunakan software akuntansi akan naik sebesar 15,845 satuan dengan asumsi $\mathrm{X}_{3}$ dan $\mathrm{X}_{2} \mathrm{X}_{3}$ tetap.Nilai koefisien $\mathrm{X}_{3}$ sebesar 0,911 dengan signifikansi 0,007 yang berarti locus of control meningkat 1 poin maka kecemasan berkomputer mahasiswa akuntansi dalam menggunakan software 


\section{JURNAL NOMINAL / VOLUME IV NOMOR 1 / TAHUN 2015}

akuntansi akan naik sebesar 0,911 satuan dengan asumsi $\mathrm{X}_{2}$ dan $\mathrm{X}_{2} \mathrm{X}_{3}$ tetap.Nilai koefisien $\mathrm{X}_{2} \mathrm{X}_{3}$ sebesar 0,164 dengan signifikasi 0,027 yang berarti variabel moderasi meningkat 1 poin maka kecemasan berkomputer mahasiswa akuntansi dalam menggunakan software akuntansi akan turun sebesar $-0,164$ satuan dengan asumsi $\mathrm{X}_{2}$ dan $\mathrm{X}_{3}$ tetap.

2) Hasil Uji F

Hasil penelitian ini diperoleh nilai $F_{\text {hitung }}=6,545>F_{\text {tabel }}=3,91$, maka dapat dinyatakan bahwa IPK berpengaruh terhadap kecemasan berkomputer mahasiswa akuntansi dalam menggunakan software akuntansi dengan locus of control sebagai variabel moderasi.

3) H6: Terdapat pengaruh karakteristik tipe kepribadian dan IPK terhadap kecemasan berkomputer mahasiswa akuntansi dalam menggunakan software akuntansi dengan locus of control sebagai variabel moderasi.

Tabel 9. Rangkuman Hasil Analisis MRA

\begin{tabular}{ll}
\hline \multicolumn{1}{c}{ Variabel } & \multicolumn{1}{c}{$\begin{array}{c}\text { Koefisien } \\
\text { Regresi }\end{array}$} \\
\hline Konstanta & $-47,341$ \\
\hline Karakteristik Tipe Kepribadian & 3,794 \\
\hline IPK & 15,570 \\
\hline Locus of Control & 1,123
\end{tabular}

\begin{tabular}{ll}
\hline $\mathrm{M}$ & $-0,017$ \\
$\mathrm{R}$ & 0,524 \\
\hline Adjusted RSquare & 0,252 \\
\hline F Hitung & 12,031 \\
\hline Sig F & 0,000 \\
\hline Sig Karakteristik & 0,004 \\
Kepribadian & \\
\hline Sig IPK & 0,002 \\
\hline Sig Locus of Control & 0,002 \\
\hline Sig Moderasi & 0,023
\end{tabular}

1) Persamaan Garis Regresi

Berdasarkan tabel di atas diperoleh persamaan untuk hipotesis 6 sebagai berikut:

$Y=-47,341+3,794 X_{1}+15,570 X_{2}+$ $1,123 \mathrm{X}_{3}-0,017 \mathrm{X}_{1} \mathrm{X}_{2} \mathrm{X}_{3}$

Nilai koefisien $\mathrm{X}_{1}$ sebesar 3,794 dengan signifikansi 0,004 yang berarti karakteristik tipe kepribadian meningkat 1 poin maka kecemasan berkomputer mahasiswa akuntansi dalam menggunakan software akuntansi akan naik sebesar 3,794 satuan dengan asumsi $\mathrm{X}_{2}, \mathrm{X}_{3}$ dan $\mathrm{X}_{1} \mathrm{X}_{2} \mathrm{X}_{3}$ tetap.Nilai koefisien $X_{2}$ sebesar 15,570 dengan signifikansi 0,002 yang berarti IPK meningkat 1 poin maka kecemasan berkomputer mahasiswa akuntansi dalam menggunakan software akuntansi akan naik sebesar 15,570 satuan dengan asumsi $\mathrm{X}_{1}, \mathrm{X}_{3}$ dan $\mathrm{X}_{1} \mathrm{X}_{2} \mathrm{X}_{3}$ tetap. Nilai koefisien $\mathrm{X}_{3}$ sebesar 1,123 dengan 


\section{JURNAL NOMINAL / VOLUME IV NOMOR 1 / TAHUN 2015}

signifikansi 0,002 yang berarti locus of control meningkat 1 poin maka kecemasan berkomputer mahasiswa akuntansi dalam menggunakan software akuntansi akan naik sebesar 1,123 satuan dengan asumsi $\mathrm{X}_{1}, \mathrm{X}_{2}$ dan $\mathrm{X}_{1} \mathrm{X}_{2} \mathrm{X}_{3}$ tetap.

\section{2) Hasil Uji F}

Hasil penelitian ini diperoleh nilai $F_{\text {hitung }}=12,031>F_{\text {tabel }}=3,92$, maka dapat dinyatakan bahwa karakteristik tipe kepribadian dan IPK berpengaruh terhadap kecemasan berkomputer mahasiswa akuntansi dalam menggunakan software akuntansi dengan locus of control sebagai variabel moderasi.

\section{SIMPULAN DAN SARAN}

\section{Simpulan}

a. Terdapat pengaruh karakteristik tipe kepribadian terhadap kecemasan berkomputer mahasiswa akuntansi dalam menggunakan software akuntansi. Hal ini ditunjukkan oleh nilai $\mathrm{t}_{\text {hitung }} 4,465>\mathrm{t}_{\text {tabel }} 1,9781$ dan nilai koefisien korelasi (r) sebesar 0,377.

b. Terdapat pengaruh IPK terhadap kecemasan berkomputer mahasiswa akuntansi dalam menggunakan software akuntansi. Hal ini ditunjukkan oleh nilai $t_{\text {hitung }} 2,972>t_{\text {tabel }} 1,9781$ dan nilai koefisien korelasi (r) sebesar 0,252. c. Terdapat pengaruh karakteristik tipe kepribadian dan IPK secara bersamasama terhadap kecemasan berkomputer mahasiswa akuntansi dalam menggunakan software akuntansi. Hal ini ditunjukkan oleh nilai $F_{\text {hitung }} 14,436$ $>\mathrm{F}_{\text {tabel }}$ 3,91 dan nilai koefisien korelasi (R) sebesar 0,428.

d. Terdapat pengaruh karakteristik tipe kepribadian terhadap kecemasan berkomputer mahasiswa akuntansi dalam menggunakan software akuntansi dengan locus of control sebagai variabel moderasi. Hal ini ditunjukkan oleh signifikansi interaksi antara karakteristik tipe kepribadian dan locus of control sebesar $0,013<0,05$. Nilai $F_{\text {hitung }} 14,495>F_{\text {tabel }}$ 3,91 dan nilai koefisien korelasi (R) sebesar 0,377.

e. Terdapat pengaruh IPK terhadap kecemasan berkomputer mahasiswa akuntansi dalam menggunakan software akuntansi dengan locus of control sebagai variabel moderasi. Hal ini ditunjukkan oleh signifikansi interaksi antara IPK dan locus of control sebesar $0,013<0,027$. Nilai $F_{\text {hitung }} 6,545>F_{\text {tabel }}$ 3,91 dan nilai koefisien korelasi (R) sebesar 0,365 .

f. Terdapat pengaruh karakteristik tipe kepribadian dan IPKsecara bersamasama terhadap kecemasan berkomputer mahasiswa akuntansi dalam menggunakan software akuntansi 


\section{JURNAL NOMINAL / VOLUME IV NOMOR 1 / TAHUN 2015}

dengan locus of control sebagai variabel moderasi. Hal ini ditunjukkan oleh signifikansi interaksi antara karakteristik tipe kepribadian, IPK dan locus of control sebesar $0,013<0,023$. Nilai $F_{\text {hitung }}$ 12,031> $F_{\text {tabel3,92dan nilai }}$ koefisien korelasi (R) sebesar 0,524.

g. Variabel karakteristik tipe kepribadian memberikan sumbangan relatif sebesar $28 \%$ dan sumbangan efektif sebesar 7\%. Variabel IPK memberikan sumbangan relatif sebesar $35 \%$ dan sumbangan efektif sebesar $9 \%$. Variabel locus of control memberikan sumbangan relatif sebesar $37 \%$ dan sumbangan efektif sebesar 9\%. Variabel karakteristik tipe kepribadian, IPK dan locus of control memberikan sumbangan efektif sebesar $25 \%$.

\section{Saran}

Berdasarkan kesimpulan dan hasil penelitian tersebut, maka diajukan saran-saran sebagai berikut:

1. Mahasiswa akuntansi yang mengalami kecemasan berkomputer dalam menggunakan software akuntansi karena mahasiswa mengalami kesulitan dalam memahami aspek teknik komputer meliputi hardware, software, dan brainware saat menggunakan software akuntansi, sebaiknya mahasiswa mempelajari aspek teknik komputer untuk melakukan antisipasi agar dapat mengatasi kecemasan berkomputer dalam menggunakan software akuntansi sehingga mahasiswa lebih mengerti tentang software akuntansi, karena dapat meningkatkan kemampuan serta dapat mengetahui cara mengatasi kesulitan tersebut.

2. Berdasarkan data responden skor terendah pada indikator anticipation adalah pada pernyataan tantangan dalam mempelajari software akuntansi itu sangat menyenangkan (exciting), mahasiswa yang mempelajari software akuntansi sebaiknya menganggap bahwa mempelajari software akuntansi merupakan tantangan, tapi bukan menganggapnya beban.

3. Berdasarkan data responden skor terendah pada indikator internal locus of control adalah pada pernyataan karir saya sepenuhnya tergantung dari hasil kerja saya. Mahasiswa dengan kinerja yang masih kurang dapat meningkatkan kinerjanya agar kedepannya dapat meningkatkan karir mahasiswa.

4. Mahasiswa untuk dapat menjadi orang terbaik dalam suatu pekerjaan seharusnya tidak terlalu bergantung pada keberuntungan namun harus percaya pada diri sendiri dengan meningkatkan kinerja dalam pekerjaannya.

5. Karakteristik tipe kepribadian, IPK dan locus of control berpengauh 27,5\% 
JURNAL NOMINAL / VOLUME IV NOMOR 1 / TAHUN 2015

terhadap kecemasan berkomputer mahasiswa akuntansi dalam menggunakan software akuntansi. Sedangkan $72,5 \%$ sisanya dijelaskan oleh faktor lain di luar penelitian ini. Untuk itu perlu adanya penelitian lebih lanjut tentang faktor-faktor yang mempengaruhi kecemasan berkomputer mahasiswa akuntansi dalam menggunakan software akuntansi. Penelitian selanjutnya sebaiknya untuk menggunakan sampel lebih luas, tidak hanya dalam lingkungan Prodi Akuntansi dalam satu Universitas.

\section{DAFTAR PUSTAKA}

Ladislaus Naisaban. (2003). Psikologi Jung: Tipe Kepribadian Manusia dan Rahasia Sukses Dalam Hidup (tipe kebijaksanaan Jung). Jakarta : PT Gramedia.

Syaiful Ali dan Fadila. (2008). Kecemasan Berkomputer (Computer Anxiety) Dan Karakteristik Tipe Kepribadian Pada Mahasiswa Akuntansi. SNA 11.Pontianak.

Reno Fitri Meuthia. \& Wiwik Andriani. (2003). Studi Korelasi Antara Indeks Prestasi Kumulatif (IPK) dengan Nilai Ujian Komprehensif Mahasiswa Jurusan Akuntansi Politeknik Negeri Padang. Jurnal R\&B3.Politeknik Negeri Padang.
Rizky Dwie Setyawan. (2014).

Kecemasan Berkomputer dalam

Konteks Pendidikan Akuntansi: Hubungan Tipe Kepribadian, Gender, IPK dan Pengalaman Berkomputer. Jurnal. Fakultas Ekonomi Universitas Maritim Raja Ali Haji Tanjung Pinang.

Ronowati Tjandra. (2007). Computer Anxiety dari Perspektif Gender dan Pengaruhnya Terhadap Keahlian Pemakai Komputer dengan Variabel Moderasi Locus of Control. Tesis. Program Pascasarjana Universitas Diponegoro.

Sugiyono. (2008). Metode Penelitian Kuantitatif, Kualitatif dan $R \& D$. Bandung: Alfabeta.

Suharsimi Arikunto. (2005). Prosedur Penelitian dan Pendekatan Praktek. Jakarta: Rineka Cipta.

Sutrisno Hadi. (2004). Analisis Regresi. Yogyakarta : Andi Offset.

Wijaya T. dan Johan. (2005). Pengaruh Computer Anxiety Terhadap Keahlian Penggunaan Komputer, Jurnal Pendidikan Terbuka dan Jarak Jauh, Vol. 6, No. 1. 